\title{
A reorganização das retaguardas administrativas de governo para a melhoria dos serviços públicos eletrônicos
}

European Commission. Directorate General for Information Society and Media*

\section{Introdução e contextualização}

\section{O governo eletrônico}

O modo pelo qual somos governados na Europa vem sofrendo mudanças dramáticas, para as quais a introdução das TICs (Tecnologias de Informação e Comunicação) contribui de mãos dadas com outras tendências sociais, de forma determinante.

A Comissão Européia ${ }^{1}$ defende que essas novas tecnologias podem ajudar as administrações públicas a lidarem com os mais variados desafios. O foco, entretanto, não deve ser lançado meramente sobre a TIC, mas no seu uso combinado com a mudança organizacional e as novas práticas que visem à melhoria dos serviços públicos, dos processos democráticos e das políticas públicas. É disso que se trata o governo eletrônico. Possibilita-se, por meio dele, administrar melhor e de forma mais eficiente, aperfeiçoar o desenvolvimento e a implementação de políticas públicas e auxiliar o setor público na conflituosa tarefa de atender os 
cidadãos e prestar serviços em maior quantidade e melhor qualidade com menos recursos.

O governo eletrônico permite também manter e fortalecer a governança na sociedade do conhecimento. Isso significa um setor público ${ }^{2}$ :

- aberto e transparente, ou seja, governos "compreensíveis", que prestem conta aos cidadãos e sejam receptivos à participação e ao escrutínio democráticos;

- a serviço de todos, isto é, seja focado no usuário e seja inclusivo, o que significa que ninguém será excluído da prestação de seus serviços e se respeitará cada um como indivíduo, fornecendo-lhe atendimento personalizado;

- produtivo, que devolve o máximo em valor pelo dinheiro pago pelos contribuintes, o que implica que menos tempo será desperdiçado em filas, erros serão reduzidos drasticamente, mais tempo será destinado ao atendimento pessoal e o trabalho do servidor público tornar-se-á mais compensador.

Nos últimos anos, os conceitos de governo e governança transformaram-se profundamente. Isso se deve às crescentes pressões e expectativas não somente para que sejamos governados por métodos modernos que resultem em eficiência e eficácia (deve-se "fazer mais por menos", ano a ano), mas também para que os governos sejam mais abertos à accountability democrática.

Este caldeirão de mudanças encontrase agora, mais uma vez, a ponto de ferver em razão do impacto causado pelas novas tecnologias digitais no governo. Como muitos confirmam, o governo eletrônico permite que eficiência e democracia se encontrem de forma mais fácil e barata do que se pensava inicialmente, e a aplicação de TICs possibilita a redução do trade-off que sempre existiu entre esses dois objetivos admiráveis. As novas tecnologias, porém, vão muito além. Elas começam a redefinir a paisagem de governo, alterando as relações (de poder e responsabilidade) e envolvendo os diferentes atores - entre os fornecedores de serviço e o setor produtivo, entre o público, o privado e o terceiro setor e entre o governo e o cidadão.

Emergem, nesse cenário, novas formas de governança, refletindo a transformação, entre outros, das estruturas organizacionais e econômicas, com conseqüências profundas sobre a maneira como compreendemos e exercemos a cidadania. Fica claro que governo eletrônico não significa apenas colocar os serviços públicos on-line e melhorar sua prestação, mas constitui também um conjunto de processos, mediados pela tecnologia, que podem modificar as interações, em uma escala maior, entre os cidadãos e o governo.

\section{O governo eletrônico e a prática de benchmarking}

$\mathrm{O}$ movimento em direção à adoção do governo eletrônico e a necessidade de reforma administrativa são parte crescente da agenda política da maioria dos países europeus. A rápida difusão do uso da Internet, além disso, tem resultado na ampliação da oferta de serviços eletrônicos disponibilizados por instituições de governo aos cidadãos e a pessoas jurídicas.

A UE conferiu também grande peso à constatação urgente dos ganhos econômicos e sociais potenciais associados à sociedade da informação. Em 2000, a Comissão Européia ${ }^{4}$ deu início ao eEurope, tendo como objetivos principais:

- colocar cada cidadão, escola, negócio e administração on-line;

- criar uma Europa digitalmente alfabetizada, apoiada por uma cultura 
empreendedora pronta para prover o financiamento necessário;

- assegurar que todo esse processo seja inclusivo, alimentando a confiança do consumidor e fortalecendo a coesão social.

- Para tanto, a Comissão propôs dez áreas prioritárias como parte do Plano de Ação eEurope 2002, com metas ambiciosas a serem alcançadas por meio da atuação conjunta da Comissão, dos Estadosmembros, do setor produtivo e dos cidadãos europeus. Uma delas foi o "governo on-line", que buscava garantir que os cidadãos tivessem fácil acesso on-line às informações sobre o governo, aos serviços e aos procedimentos de tomada de decisão. Esses serviços públicos eletrônicos estão hoje disponíveis nos níveis supranacional (por exemplo, G8, OECD), nacionais e locais das políticas de todos os Estados-membros (por exemplo, OL2000 nos Países Baixos, Dinamarca Digital (Digital Denmark), Modernizando o Governo (Modernizing Government) no Reino Unido, etc.).

A maioria dos Estados-membros adotou ou está em processo de adotar estratégias de governo eletrônico para a provisão de serviços on-line para cidadãos e pessoas jurídicas. ${ }^{5} \mathrm{O}$ alvo do eEurope era disponibilizar todos os serviços básicos online até o fim de 2002. O Conselho de Mercado Interno chegou a uma definição de quais seriam os serviços básicos, estabelecendo oito destinados a pessoas jurídicas e 12 a cidadãos, como mostra a tabela a seguir.

Dois grupos de indicadores desses serviços de governo eletrônico estão sendo pesquisados:

- porcentagem dos serviços públicos básicos disponíveis on-line; e

- uso dos serviços públicos on-line pelo público, para fins de obtenção de informação ou submissão dos formulários.
O progresso em tornar esses serviços on-line é medido por uma estrutura de referência em quatro estágios: 1) disponibilização da informação on-line; 2) interação de mão única; 3) interação de mão dupla; e 4) transações on-line completas, incluindo entrega e pagamento.

Esses dados têm sido coletados duas vezes ao ano.

Para além da provisão e utilização dos serviços públicos eletrônicos, há também

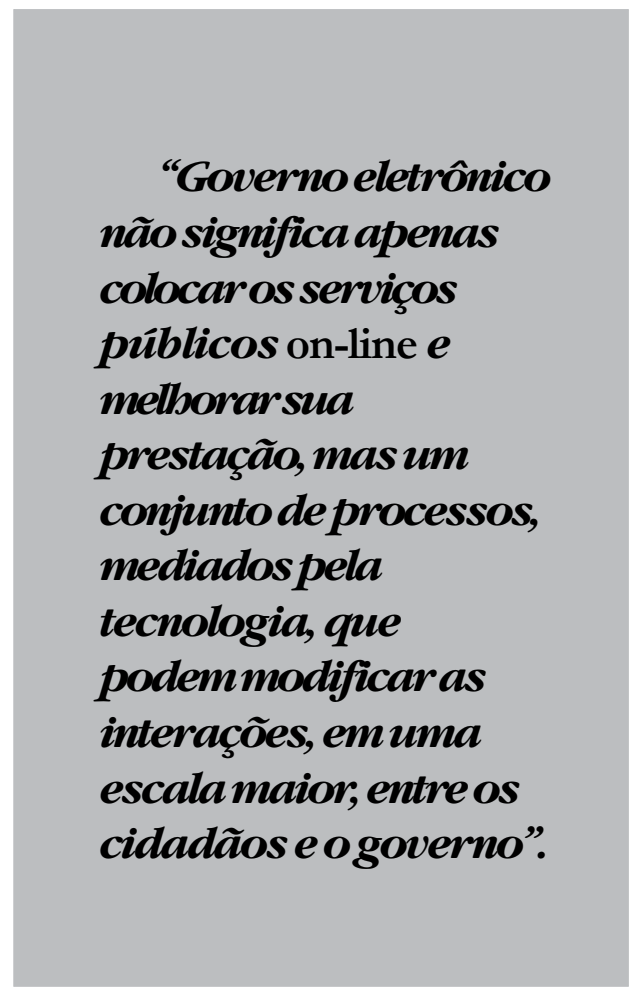

uma questão de governança: "Publicar as agendas dos conselhos na Internet, possibilitar o voto eletrônico ou disponibilizar os endereços eletrônicos de políticos não irá, por si, deter o distanciamento dos eleitores [...] ou restabelecer a confiança nas instituições públicas e nas estruturas de tomada de decisão". ${ }^{6} \mathrm{O}$ governo eletrônico pode ser tão-somente uma ferramenta para conseguirmos uma 
A lista comum dos 20 serviços públicos básicos do eEurope

\begin{tabular}{|c|c|}
\hline & Serviços públicos para os cidadãos \\
\hline 1 & Imposto sobre a renda: declaração, notificação de lançamento \\
\hline 2 & Busca de emprego por meio de postos de intermediação de mão-de-obra \\
\hline 3 & $\begin{array}{l}\text { Contribuições à seguridade social: } \\
\text { a) benefícios por desemprego } \\
\text { b) pensões familiares } \\
\text { c) gastos médicos (reembolsos ou pagamentos diretos) } \\
\text { d) bolsas de estudos }\end{array}$ \\
\hline 4 & $\begin{array}{l}\text { Documentos pessoais: } \\
\text { a) passaporte } \\
\text { b) carteira de habilitação }\end{array}$ \\
\hline 5 & Registro de veículo (novos, usados ou importados) \\
\hline 6 & Requerimento de licença para construção \\
\hline 7 & Boletim de ocorrência policial (ex.: em caso de roubo) \\
\hline 8 & Bibliotecas públicas (disponibilidade no catálogo, mecanismos de busca) \\
\hline 9 & $\begin{array}{l}\text { Requerimento e entrega de certidões de: } \\
\text { a) nascimento } \\
\text { b) casamento }\end{array}$ \\
\hline 10 & Matrícula em curso superior/universidade \\
\hline 11 & Alteração de endereço \\
\hline 12 & $\begin{array}{l}\text { Serviços de saúde (ex.: aconselhamento interativo sobre disponibilidade de } \\
\text { serviços em diferentes hospitais, marcação de consultas, etc.) } \\
\text { Serviços públicos para pessoas jurídicas }\end{array}$ \\
\hline 13 & Contribuição social para empregados \\
\hline 14 & Imposto sobre a renda das pessoas jurídicas: declaração e notificação \\
\hline 15 & Imposto sobre o valor agregado (IVA): declaração e notificação \\
\hline 16 & Registro de abertura de empresa \\
\hline 17 & Envio de dados para os órgãos de estatística \\
\hline 18 & Declarações aduaneiras \\
\hline 19 & Permissões ambientais (inclusive relatórios) \\
\hline 20 & Licitações \\
\hline
\end{tabular}

governança mais aberta, mais participativa, mais accountable, mais eficaz e mais coerente (cf. declaração ministerial da Conferência sobre Governo Eletrônico, realizada em Bruxelas, em 29 e 30 novembro 2001, que indica também que atenção crescente deve ser dada à provisão de serviços de governo eletrônico pan-europeus).
Este importante relatório mostra como a economia eletrônica (e-economy) está emergindo na Europa. ${ }^{7}$ Aponta contrastes agudos e um retrato variado no que tange à chegada da sociedade da informação nos Estados-membros da UE. As principais conclusões sobre as políticas a serem desenhadas a partir do exercício de benchmarking são as seguintes: 
A declaração ministerial da Conferência sobre Governo Eletrônico, bem como a pesquisa de benchmarking devem criar um momento político propício ao desenvolvimento de serviços públicos on-line e à identificação das demandas por esses serviços em nível pan-europeu. Isso terá de ser complementado com um foco na reorganização do back-office (retaguarda

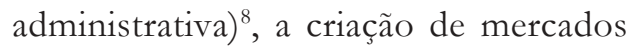
eletrônicos para as licitações e o investimento em equipamentos novos nas administrações.

\section{A definição de reorganização do back-office}

Back-office é um termo vinculado a frontoffice, que, nesse contexto, refere-se à interface do usuário com um serviço on-line. O backoffice recebe e processa a informação dada pelo usuário para que o serviço seja produzido e prestado. Isso pode ser feito de forma completamente manual, inteiramente automática ou por qualquer combinação de ambos. Em alguns casos, esse serviço é produzido por uma unidade ou um backoffice, enquanto em outros, pode envolver diversos back-offices de um mesmo órgão ou de órgãos distintos, no mesmo nível de governo ou em níveis diferentes. Uma vez reconhecida essa complexidade, é preciso uma terminologia comum para se atingir a comparabilidade.

Usamos o conceito de órgão público on governamental, ${ }^{9}$ que pode ser dotado de um ou mais back-offices. Um órgão é definido como uma organização formal que tenha status legal independente e uma ou mais finalidades formais (por exemplo, uma unidade administrativa, um hospital, um órgão emissor de passaportes, uma escola, uma autoridade rodoviária, uma autoridade tributária, etc.). A diferença entre um órgão e um back-office é que este último, embora possa vir a ser uma organização formal, não é dotado de status legal independente. Um back-office pode estar situado no mesmo endereço ou em endereços diferentes de outros back-offices do órgão e se distingue um do outro por ter uma ou mais atribuições formais específicas, cumpridas por estruturas organizacionais e gerenciais próprias, embora estas se juntem no nível mais elevado do órgão público.

O termo "reorganização" refere-se às mudanças nos fluxos de trabalho (reorganização ou reengenharia de processos) na estrutura de um ou mais órgãos envolvidos, isto é, na distribuição da autoridade, das atribuições e das tarefas, que ocorrem quando serviços são disponibilizados on-line. $\mathrm{O}$ interesse pela reorganização reside na longa experiência de implementação da tecnologia da informação no governo: os maiores benefícios não provêm da simples transferência de processos encaminhados em papel diretamente para o computador, mas do uso potencial da tecnologia para reestruturar esse processo, verificar se cada etapa é ainda necessária, se as etapas podem ser fundidas, etc. Para o usuário, em termos de qualidade do serviço, essa reestruturação pode significar mudança na maneira pela qual o produto é prestado. Por exemplo, alguns órgãos passaram de uma atitude passiva de recebimento dos requerimentos para a prestação proativa do serviço, com base nas informações (tais como datas) disponíveis no sistema.

\section{As principais estratégias de boas práticas}

Uma análise detalhada das 29 boas práticas estudadas identificou oito principais escolhas estratégicas entre as iniciativas de 
governo eletrônico européias mais avançadas. Elas representam as principais abordagens bem-sucedidas no uso da TIC, para melhorar os serviços e/ou reorganizar back-offices. Deve-se enfatizar que tais estratégias não são, por óbvio, excludentes, mas geralmente são combinadas de diversas maneiras, dependendo das circunstâncias, necessidades e aspirações. São elas:

- digitalização de back-offices muito pouco alterados - normalmente, quando os arranjos preexistentes de back-offices funcionam bem, é fácil digitalizar sem mudanças significativas, garantindo a alta qualidade dos serviços on-line a serem implementados aos usuários;

- reorganização profunda dos backoffices - essa estratégia se faz necessária quando os arranjos preexistentes são complexos, não integrados e talvez em crise, demandando reorganização significativa a fim de implementar serviços de alta qualidade aos usuários;

- centralização das funções de back-office e descentralização das funções de front-office - traduz-se na racionalização de back-offices e de suas atribuições (ex.: armazenamento de informações e gerenciamento) de forma a aumentar a eficiência e poupar gastos, reconhecendo, porém, que os usuários poderão necessitar de atendimento local e adaptação;

- uma "câmara de compensação" do back-office - uma estratégia útil quando os arranjos são relativamente complexos e muitas vezes não integrados, mas difíceis de serem modificados. Assim, um mecanismo de troca de dados à parte é estabelecido para uso tanto dos órgãos como dos usuários, assegurando a alta qualidade dos serviços on-line.

- tipos genéricos de interação entre usuário e órgão - possibilitam importantes ganhos de escala e escopo, modulando o back-office ou componentes de serviços em área abrangente e reduzindo, por outro lado, a flexibilidade para adaptar-se a exigências específicas;

- portais - uma abordagem focada no usuário, que apresenta pacotes de serviços preexistentes em formato e contexto adequados para atividades e perfis específicos de usuários;

- serviços proativos - considerando que os back-offices estão cada vez mais integrados e capazes de compartilhar dados e recursos entre eles, é possível oferecer serviços que requerem pouca ou nenhuma iniciativa ou ação do usuário, poupandolhe, assim, tempo, gastos e esforço;

- maior responsabilidade e controle do usuário - a maior integração e a interoperabilidade do back-office conferem aos usuários maior responsabilidade e iniciativa, de forma que o próprio usuário possa determinar precisamente onde, quando e como o serviço deve ser utilizado.

\section{Digitalização de back-offices muito pouco alterados}

O rápido progresso em matéria de governo eletrônico depende freqüentemente da existência ou não de uma história de integração e cooperação do back-office, particularmente se há um legado tecnológico interoperável. Assim, o legado organizacional histórico e tecnológico desempenha papel decisivo: quando o backoffice preexistente é relativamente bem integrado e bem-sucedido, pode não ser preciso empreender mudanças organizacionais ou até mesmo tecnológicas significativas por ocasião da introdução de serviços eletrônicos. Em muitos casos, pode até ser bastante fácil e rápido digitalizar os fluxos de trabalho e as interconexões organizacionais existentes e/ 
ou erguer um front-office virtual usando a tecnologia da web sobre a tecnologia legada do back-office, ou mesmo alguma combinação de ambos. Em tais casos, a integração existente do back-office é mais ou menos cimentada como inicialmente era. Por um investimento relativamente modesto, essa mudança pode trazer uma economia não insignificante, empregos melhores, serviços melhores, mais rápidos e mais transparentes aos usuários e maior interação com eles, conferindo-lhes, por exemplo, mais acesso, responsabilidade e controle.

Mesmo nos casos em que os arranjos organizacionais existentes são complicados e não necessariamente operando em condições ótimas, é improvável que a prioridade imediata seja a reorganização dos back-offices ou dos fluxos de trabalho, se o serviço tradicionalmente oferecido estiver funcionando relativamente bem e não estiver em crise. No entanto, o que tipicamente se observa nessa estratégia é que os serviços são colocados on-line mesmo assim, o que leva a melhorar a qualidade do serviço para os usuários e poupar gastos para os órgãos, bem como melhorar as condições de trabalho da equipe.

Além disso, essas melhorias, se comparadas às iniciativas que requerem reorganização ou investimentos em tecnologia em grande escala, são, muitas vezes, relativamente fáceis e pouco custosas, porque não há - ou há pequenas - mudanças organizacionais ou de fluxos de trabalho e não existem estruturas novas de processo do trabalho a introduzir. Assim, digitalizar um back-office em grande parte inalterado e/ou construir um frontoffice por cima deste oferece a vantagem de evitar que sistemas existentes tenham seu desenvolvimento prejudicado, estimulando o aperfeiçoamento do serviço existente na Internet.

Um exemplo relevante dessa estratégia de boa prática é a declaração aduaneira da Austria para o comércio de bens e serviços fora do âmbito da UE, que se iniciou a partir das pressões exercidas pela comunidade empresarial austríaca. A demanda não advinha de um serviço inerentemente deficiente, como os serviços aduaneiros o são tradicionalmente, mas da oferta de melhores serviços por rivais em outros países da UE, que os haviam colocado online, fato que resultou na ameaça de importadores e exportadores austríacos de retirarem seus negócios do país.

No caso da declaração aduaneira da Áustria:

- os arranjos organizacionais existentes eram relativamente simples e bem integrados, de modo que apenas uma pequena reorganização se fazia necessária;
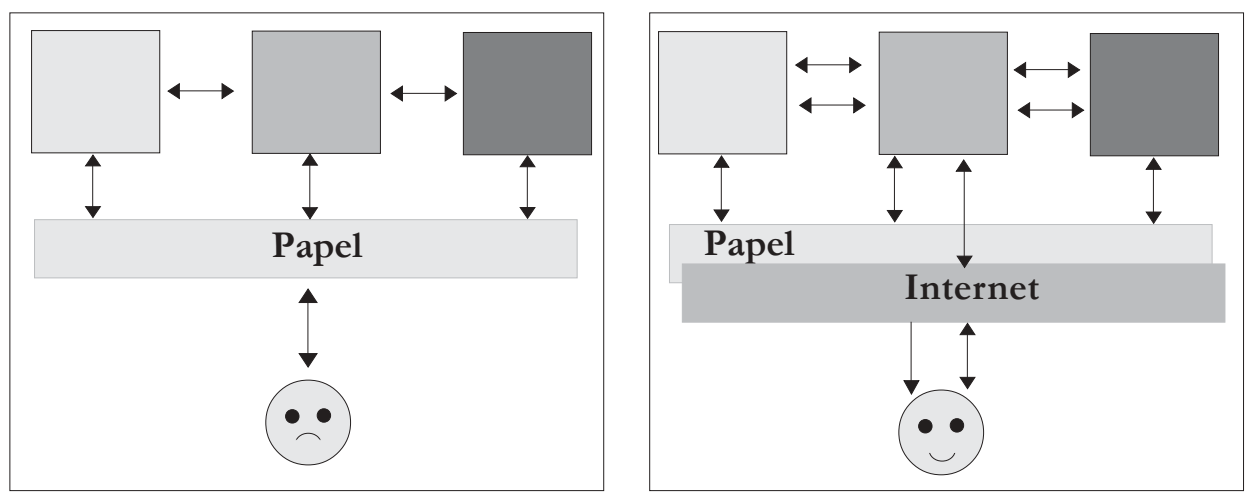
- a solução tecnológica para a introdução do serviço eletrônico foi digitalizar arquiteturas e fluxos de trabalho existentes e disponibilizar um balcão de atendimento com base na web;

- as funções, tarefas e habilidades de trabalho da equipe mudaram para melhor, alguns membros da equipe foram liberados para outras funções e outros custos foram reduzidos;

- houve considerável descentralização da responsabilidade e controle diretamente aos próprios usuários (do ramo de importação e exportação), possibilitando acesso a um serviço mais ágil, preciso e satisfatório.

Outros exemplos de digitalização de back-offices que permaneceram praticamente iguais incluem:

\section{Serviços eletrônicos aos cidadãos:}

- imposto de renda na França: ainda que se tenha colocado o serviço on-line, o princípio básico das declarações de imposto de renda não foi alterado como resultado da digitalização: a mesma informação tem de ser prestada basicamente no mesmo período do ano; o que era, no passado, feito por via postal e pagamento tradicional, hoje pode ser feito pela Internet;

- registro de veículos na Itália e nos Países Baixos: em ambos os casos, a digitalização conduziu a uma reorganização na provisão do serviço, tendo em vista que determinadas bases de dados passaram a ser digitalmente conectadas, e também a mudanças nas etapas de trabalho da equipe e dos usuários, as quais, porém, não envolveram nenhuma alteração na organização dos back-offices;

- concessões de bolsas de estudos na Dinamarca. neste caso, somente uma interface web foi colocada sobre a estrutura de cooperação organizacional, sobre os fluxos de trabalho e sobre os legados tecnológicos existentes, resultando em um trabalho muito menor e mais interessante para a equipe e em serviço muito mais responsivo e acessível aos usuários, aos quais foram conferidos mais responsabilidade e controle;

- benefícios sociais, bibliotecas públicas na Dinamarca e boletim de ocorrência policial na Finlândia: em ambos os casos, pouca ou nenhuma mudança ou integração foi necessária na estrutura organizacional existente, que funcionava bem. Na Dinamarca, sistemas eletrônicos novos, flexíveis e altamente compatíveis foram colocados por cima dos softwares existentes, que que variam de biblioteca para biblioteca. Na Finlândia, nova tecnologia foi instalada na interface com o cidadão, também tendo como alicerce um sistema preexistente, o que levou a uma rápida disseminação do serviço e adesão a ele;

- licença para construção na Bolonha, Itália: as etapas de trabalho existentes equipararam-se ao conteúdo disponível on-line tanto quanto possível, sem grande reorganização do serviço;

- matrícula no ensino superior no Reino Unido: havia um longo e estável relacionamento entre as partes interessadas, de modo que a digitalização e a integração foram relativamente fáceis e bem-sucedidas.

\section{Serviços eletrônicos às pessoas jurídicas: \\ - registro de empresas novas na Itália: houve} aqui pouca ou nenhuma mudança nos arranjos organizacionais e na integração existentes, sucedendo-se apenas a digitalização dos fluxos de trabalho;

- licitações na Áustria: o serviço SBA on-line $e^{10}$ baseou-se na necessidade de mudanças na provisão do serviço e desencadeou pequenas modificações na organização dos back-offices, dado que o novo serviço on-line envolvia atores que já 
cooperavam há muito tempo na compra de livros escolares. A reorganização dos back-offices não foi empreendida, uma vez que não havia necessidade ou alternativa para mudar as estruturas organizacionais;

- portais na Espanha e na Suécia: em ambos os casos, não foi preciso recomeçar as mudanças da estaca zero; na Espanha, a maioria dos processos e das rotinas de trabalho entre os diferentes órgãos já era comum antes da criação do portal; os desafios principais relacionaram-se, conseqüentemente, à integração dos sistemas de TI do usuário (front-end) e do servidor (back-end), à integração com bancos, às questões de segurança e estrutura legal; na Suécia, as relações organizacionais e a integração dos dados, inclusive com bancos, já existiam antes da introdução de serviços na web.

\section{Reorganização profunda dos back-offices}

Como descrito na seção anterior, uma importante consideração a ser feita por ocasião da introdução de serviços on-line que busquem a racionalização e a obtenção de benefícios qualitativos é a existência de história de integração e cooperação de back-offices, particularmente se houve a incorporação de legado tecnológico interoperável. A configuração

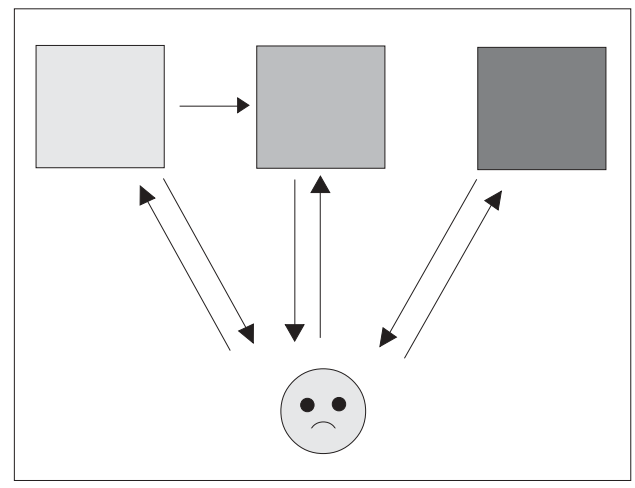

organizacional vê-se diretamente refletida na tecnologia que a sustenta. De fato, eles são, não raro, mutuamente dependentes, de modo que uma mudança profunda em uma implica mudança profunda em outra, fazendo com que modificações se tornem mais desafiadoras, potencialmente difíceis e custosas em termos de tempo e recursos.

Entretanto, uma mudança profunda pode ser necessária se os back-offices estiverem funcionando mal em qualquer grau significativo e/ou o serviço seja incompatível a padrões aceitáveis ou a demandas recorrentes de usuários. Se a mudança é motivada por tal crise, por iniciativas do governo central ou, ainda, por outros vetores, o fato é que as recompensas, por outro lado, podem ser também consideráveis, e não somente a longo prazo.

A decisão de dar andamento a uma profunda reorganização dos back-offices e as mudanças concomitantes dos front-offices possibilitam - e, na verdade, levam a repensar totalmente o sistema e a filosofia do desenho, a produção e a entrega do serviço a partir do zero. O recomeço pode ser necessário em cenários de back-offices mal integrados, pelo menos com relação às demandas provenientes da digitalização, ou de legados tecnológicos incompatíveis (ou cuja compatibilização resulte demasiadamente cara) para continuarem a ser usados ao se aperfeiçoarem os serviços.

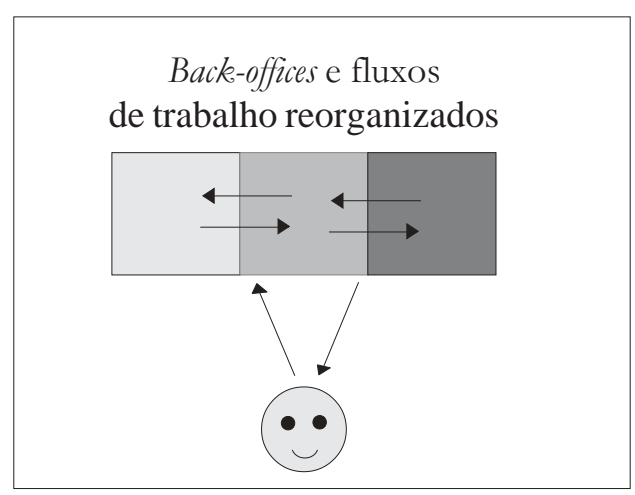


As tecnologias digitais, independentemente do peso que a TIC exerce sobre a estrutura, vêm provando ser excelente catalisador e meio importante de reforma sempre que um serviço não funciona bem, encontra-se inerentemente em crise ou necessita, de qualquer forma, de mudança.

Uma profunda reorganização de backoffices envolve normalmente reflexão sobre a totalidade da organização e a entrega dos serviços, das estruturas de processo de trabalho e da interoperabilidade entre os back-offices e as diferentes organizações.

Um exemplo relevante dessa estratégia de boa prática é a concessão de bolsas de estudo nos Países Baixos, que necessitava de urgente aperfeiçoamento nos serviços e nas relações com o cliente, cuja solução, por sua vez, poderia melhorar a percepção pública do IB-Grupo, responsável pela administração de financiamentos estudantis e de outros serviços destinados a esse público. Em 2000-2001, o IBGrupo tinha reputação extremamente negativa, decorrente dos fracos desempenhos nos anos anteriores. O grupo reconhecia que a relação com seus clientes melhoraria apenas a partir da melhora geral de seu desempenho e a única maneira de se conseguir isso era iniciar mudanças fundamentais em ambas as pontas da organização: rever os serviços aos clientes resultaria em maior eficiência no front-office, o que implicaria, em larga medida, realizar mudanças dramáticas nos back-offices e repensar, por completo, a maneira pela qual o serviço era organizado.

No caso holandês da concessão de bolsas estudantis:

- o serviço necessitava de reforma (ele estava, de fato, em crise e enfrentava questionamentos no Parlamento holandês), independentemente da introdução ou não das tecnologias digitais;
- os arranjos organizacionais legados eram relativamente complexos e não bem integrados, demandando ampla reorganização do back-office e das relações entre os órgãos, o que poderia gerar resistência dos níveis hierárquicos mais baixos e de gerentes dos departamentos. Na prática, porém, isso não constituiu problema, porque o motor para a mudança veio das próprias equipes e dos usuários;

- a solução de tecnologia adotada foi absolutamente fundamental e seus resultados superaram as expectativas, agregando não apenas uma interface web ao sistema legado, mas digitalizando, às vezes pela primeira vez, muitos fluxos de trabalho, com a introdução de novos softwares de comunicação para permitir a cooperação entre back-offices e órgãos antes não cooperativos, etc;

- ocorreram mudanças significativas nas funções, tarefas e habilidades dos membros da equipe, muitos dos quais passaram a realizar trabalhos menos rotineiros e mais interessantes como resultado. Houve, por outro lado, perda considerável da equipe no quadro geral;

- houve descentralização da responsabilidade e controle para os próprios estudantes-usuários, não apenas em prol da exatidão dos dados e da responsividade do serviço, mas também da retirada, da equipe, tanto quanto possível, do fardo de alimentar dados no sistema.

Outros exemplos de estratégias incluem:

- a emissão de documentos pessoais para cidadãos na Áustria e, em certa medida, a emissão de certidões de nascimento e casamento em Bremen, Alemanha: ambas são caracterizadas por ampla reorganização na provisão do serviço. Enquanto a solução austríaca se caracteriza pela forte integração do front-office e do back-office com 
sofisticada provisão de serviços, que podem ser acessados integralmente on-line, a ênfase da solução de Bremen encontrase na integração do back-office responsável pela entrega do serviço com o caixa responsável por todas as transações que implicavam pagamento na administração pública;

- o pagamento de pensões familiares na Irlanda: mostra como o processo de solicitação de pagamento de benefícios à criança foi radicalmente alterado. Os avanços mais relevantes incluíram a reorganização e o desenvolvimento da interface com o usuário (back-end) do sistema de concessão do benefício à criança, bem como do procedimento de registro civil na Irlanda, que dão suporte a um processo automático e proativo de requerimento do benefício após o nascimento da criança. O redesenho desse serviço levou à implementação de nova estrutura de entrega do serviço, que envolveu a reengenharia dos sistemas de back-offices (processos e procedimentos de negociação de contratos, arquitetura da tecnologia, ferramentas, plataforma de desenvolvimento, redesenho dos sistemas legados) a partir dos canais de acesso dos usuários e da adoção de abordagem proativa/automática na disponibilização do serviço.

Pode acontecer que nem todos os aspectos necessitem de reformas estruturais, pelo menos naquele mesmo momento. Por exemplo, o foco pode cair sobre a reconfiguração de estruturas e arranjos formais, sobre os novos e integrados fluxos de trabalhos, os novos tipos de arranjos funcionais ou, ainda, a incorporação e uso de tecnologia. Reformas como essas, em andamento, podem envolver o uso continuado de redes e relações existentes, mas combinadas com uma reorganização que inclua a digitalização de fluxos de trabalho. O mesmo ocorre quando a reorganização e integração ocorrem ao longo de vários anos, de forma que somente uma reorganização parcial venha a ser necessária por ocasião da digitalização e da introdução de serviços on-line. Exemplos de mudanças parciais incluem:

"As tecnologias digitais, independentemente do peso que aTIC exerce sobre a estrutura, vêm provandoserexcelente catalisadoremeio importante de reforma sempre que um serviço nãofunciona bem, encontra-se inerentemente em crise ou necessita, de qualquer forma, de mudança".

- o imposto de renda da pessoa física na Finlândia e na Espanha: ambos resultam de mudanças de longa data e, de fato, vinculadas a pacotes de serviços que são parte do desenvolvimento de portal;

- concessão de licença para construir em Esslingen, na Alemanha e, em alguma medida, na Bolonha, Itália, nas quais mudanças parciais, mas ainda assim profundas, foram introduzidas. 
Centralização das funções de back-office e descentralização das funções de front-office

Uma importante estratégia de governo eletrônico, motivada pela necessidade de aumentar a eficiência e prover serviços mais efetivos e de melhor qualidade, é centralizar alguns ou todos os back-offices ou suas funções (ex.: armazenamento de dados). Essa concentração tem forte efeito racionalizador, que agrupa especialidades, reduz erros e atrasos e é capaz de beneficiar-se de uma economia de escala que grande número de unidades descentralizadas, empreendendo funções praticamente similares, não poderia obter.

Pode haver barreiras legais ou políticas para a centralização, bem como problemas persistentes resultantes de longa tradição de identidade própria e de atuação independente, mas, uma vez superados, a centralização traduz-se em redução de gastos significativos e serviços melhores. Um back-office centralizado pode, às vezes, surgir disfarçado de "escritório-meio" ou "centro de compartilhamento de serviços".

Concomitante à centralização do backoffice ocorre a descentralização do front-office. Se esta última poderá resultar em benefícios, depende do tipo de serviço e, particularmente, se houver ganhos diretos resultantes da prestação feita por múltiplos

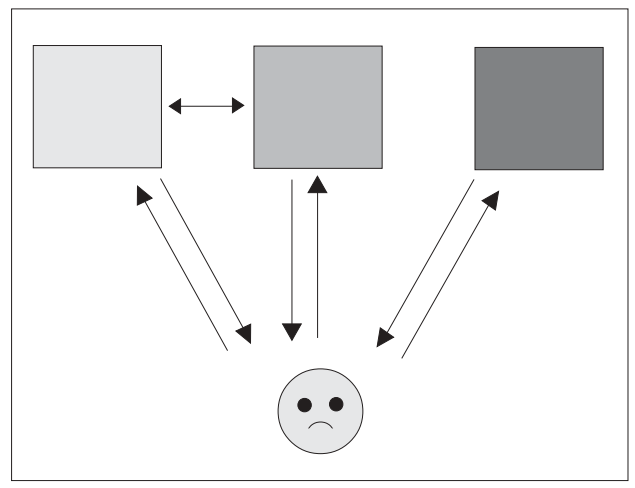

e novos canais. Essa situação pode acontecer, por exemplo, quando um serviço on-line disponibilizado por back-office centralizado ou fonte de dados é complementado por uma série de front-offices, que oferecem suporte e aconselhamento diretamente ao usuário, e, necessariamente, por conhecimento local.

Isso é importante também para atender ao interesse da democracia local e da subsidiariedade, de tal forma que a prestação do serviço seja adaptada às condições locais. Um serviço centralizado on-line complementado por afinamento local não precisa, obviamente, calcar-se apenas na prestação pessoal, já que a democracia e interesses de relevância local podem manifestar-se em serviços on-line adaptados para aquela região.

Como regra geral, a centralização do back-office e/ou de fontes de dado justifica-se quando serviços ou alguns aspectos deles são padronizados ao longo de extensa área geográfica (em geral, em um país ou Estado federal, muito embora, mesmo na Europa, eficiência e ganhos qualitativos multiplicam-se quando a centralização é possível e se justifica). Em contextos em que o serviço ou algum aspecto a ele vinculado deve responder a necessidades locais ou nos quais a prestação pessoal é parte importante do serviço, cabe descentralizar o front-office.

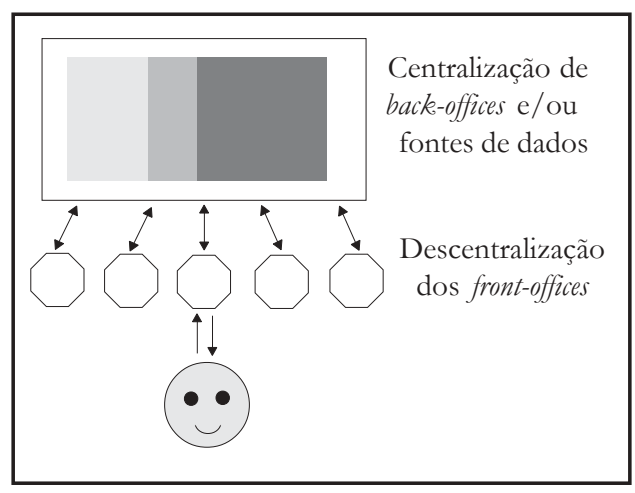


Em casos de serviços que apresentam aspectos tanto padronizados quanto vinculados à localidade da prestação, a centralização e descentralização podem claramente ser complementares.

Um exemplo relevante dessa estratégia de boa prática é o serviço de registro de veículos na Itália, que, antes do lançamento do serviço on-line, era caracterizado por inúmeras etapas a serem superadas tanto para usuários como para a equipe de servidores. Depois da compra de um automóvel, o interessado tinha de realizar cinco visitas a diferentes instituições para registrar a propriedade. Em seguida, a inscrição ou a renovação para recolhimento da taxa rodoviária constituía procedimento igualmente demorado. $\mathrm{O}$ desafio principal era, portanto, contornar essa enorme burocracia. Foi preciso, então, uma solução on-line, que centralizasse várias bases de dados mantidas por distintos órgãos. Agora, proprietários podem fazer o registro de seus veículos diretamente na concessionária, por ocasião, por exemplo, da compra do automóvel, ou ir ao órgão competente e registrá-lo com apenas uma visita. A própria equipe encarrega-se de fazer o registro on-line por meio do "e-balcão", em nome do proprietário. O resultado é uma base de dados com um "portão de entrada eletrônico" unificado, interligando as várias bases - a pública, a das concessionárias e a dos autoclubes, o que permite acesso on-line instantâneo, em qualquer tempo e lugar, a todo o sistema. Hoje, o usuário pode, ao comprar um automóvel na concessionária, fazer o registro da propriedade no local e em poucos minutos, com a ajuda de algum funcionário. Caso o veículo não seja adquirido em concessionária, ou a taxa rodoviária tenha de ser recolhida ou renovada por meio de pagamento eletrônico, fica à disposição do usuário qualquer órgão das diferentes administrações ou qualquer uma das milhares de concessionárias existentes no país, independentemente da localidade em que o veículo tenha sido inicialmente registrado.

O exemplo italiano mostra que:

- centralizar bancos de dados de backoffices sob a forma de serviço unificado e padronizado maximiza a interoperabilidade, possibilitando a sua prestação em tempo real e minimizando erros;

- descentralizar o front-office explora a extensa rede de concessionárias existente como mediadores qualificados para o registro de veículos e pagamentos eletrônicos, de maneira que recursos não precisam ser gastos na expansão, mas limitada, da rede pública de atendimento existente.

Outros exemplos de centralização de back-offices e fontes de dados e/ou de descentralização de front-offices incluem:

\section{Serviços a pessoas físicas ${ }^{11}$}

- imposto de renda na Finlândia e Espanha, que centralizou um grande número de fontes de dados em todo o país para prover um serviço unificado e de acesso instantâneo. Além disso, o caso finlandês envolve algum grau de descentralização - 446 backoffices tributários foram reduzidos a 130 , considerando que eles não atuavam, em geral, como front-offices, e que 70\% dos cidadãos aceitam um formulário previamente preenchido, que lhes é enviado como parte do serviço proativo oferecido;

- registro de automóveis nos Países Baixos: ilustra tanto a centralização de back-offices e de fontes de dados, bem como a descentralização de front-offices. Nos anos 90, proprietários de veículos fizeram intensas campanhas para a reorganização do 
procedimento de registro, que exigia registros separados em três diferentes órgãos, todas com baixa integração de dados. A reorganização resultou em uma base de dados centralizada, hoje alimentada também por grande número de outras instituições, e na completa reorganização e centralização do próprio órgão de registro. Além disso, um significativo número de front-offices adicionais foi disponibilizado, por meio da utilização da rede de concessionárias e de agências existentes dos correios;

- documentos pessoais, registro de residência na Áustria, caso em que foram desenvolvidos novos sistemas de registro, baseados na digitalização de fluxos de trabalho tanto em nível local como nacional. Um componente-chave foi o estabelecimento de um registro eletrônico central de residência em março de 2002. Antes disso, informações dessa natureza eram armazenadas em formulários de papel e em sistemas de computadores autônomos. Uma cópia do formulário de registro, que tinha o status de documento oficial, era entregue ao cidadão. Esse documento era exigido toda a vez que se fizesse necessária a comprovação de residência. Hoje, interfaces de programas permitem que órgãos públicos e um número limitado de organizações privadas busquem essa informação diretamente no órgão centralizado de registro;

- pensões familiares na Espanha, onde fontes de dados relevantes foram centralizadas para prover um serviço proativo de concessão de benefícios à criança, dentro do órgão fiscal, como parte de programa fiscal on-line mais amplo. A informação é requerida tanto para os nascimentos como para o imposto de renda pago pelas mães. O benefício à criança é visto, assim, neste caso, como abatimento no imposto, para incentivar as mães a trabalharem e é pago com a redução da carga tributária ou, alternativamente, com a restituição do montante pago;

- bolsas de estudos nos Países Baixos, onde ocorreu tanto a centralização dos back-offices do órgão competente, como parte de profunda reorganização do serviço, como a centralização dos dados de órgãos fiscais, do Escritório Central de Estatísticas, da Superintendência de Educação, de municípios, de bancos e de companhias de seguros. Além disso, deu-se início à descentralização de front-offices, pela qual 13 deles passaram a oferecer atendimento individualizado e regional na concessão de bolsas, bem como em um leque de outros serviços para estudantes;

\section{Serviços eletrônicos a pessoas jurídicas $^{12}$ \\ - imposto sobre a renda da pessoa jurídica e imposto sobre o valor agregado na Grécia, na Irlanda e em Portugal: todos apontam para a} centralização e o processamento no nível nacional, combinados com o papel de interação direta com o usuário exercido pelas agências fiscais locais. No sistema grego, as bases de dados centralizadas do Escritório Nacional para o imposto sobre o valor agregado garantiram meios para o desenvolvimento de aplicativos locais autônomos, de forma a assegurar a independência operacional das agências fiscais locais. Essa arquitetura de sistema provou ser bem-sucedida, incorporando a automação de procedimentos internos interligados em nível nacional e significativas melhorias na operação das agências locais. $\mathrm{Na}$ Irlanda, foi preciso grande esforço de digitalização e reorganização do back-office, envolvendo a integração de sistemas tributários de interface ao usuário, antes separados, no sistema de Processamento 
Integrado de Tributação, e a disponibilização de linkes eletrônicos para as agências regionais. Uma centralização de dados similar, vinculada a escritórios locais, ocorre no sistema português de imposto sobre a renda da pessoa jurídica, embora, neste caso, os principais aspectos a serem trabalhados tivessem sido a necessidade de mudança cultural e o estabelecimento de metas claras para assegurar a integração.

\section{Uma "câmara de compensa- ção" do back-office}

Uma alternativa para a centralização de fontes de dados é a criação de uma câmara de compensação do back-office. Uma base centralizada de fontes de dados contém o conjunto dos dados coletados, ou seja, dados brutos e informações analíticas. Mesmo quando eles são constantemente atualizados em sua fonte original, uma câmara de compensação possibilita a troca e interoperabilidade de dados, fornecendo ferramentas analíticas que registram e rastreiam os dados remanescentes nas bases existentes. A câmara, assim, garante a compatibilidade da troca de dados onde ela não existiria e pode constituir uma solução menos custosa em relação à centralização "no atacado" de fontes de dados que apresentem padrões de dados, linguagens, semânticas e sintaxes incompatíveis, mas que precisem comunicar-se.

Uma câmara de compensação separada pode, por vezes, surgir disfarçada de "escritórios-meio" ou "centros de serviços compartilhados". Sua função é prover uma plataforma para a interoperabilidade de dados diversos, permitindo que cada órgão continue a utilizar os dados e a tecnologia legada, bem como os seus próprios sistemas de processamento, os quais vêm sendo desenvolvidos separadamente ao longo de vários anos. A câmara, de tal forma, constitui mais propriamente um mecanismo de troca de dados ou um canal inteligente de transferência de dados do que um repositório de captura de informações. Em muitos casos, ela é terceirizada dentro do setor público ou a especialistas do setor privado.

Um exemplo relevante ${ }^{13}$ dessa estratégia de boa prática é a contribuição social devida pelos empregadores na Bélgica. Nesse caso, foi criado em 1991 um escritório público autônomo chamado Crossroads Bank for Social Security (CBSS), não para ser uma base centralizada, mas para gerir registros sobre a localização, o tipo/formato do dado necessário e seu nível de acesso (por quem e com que fim os dados poderiam
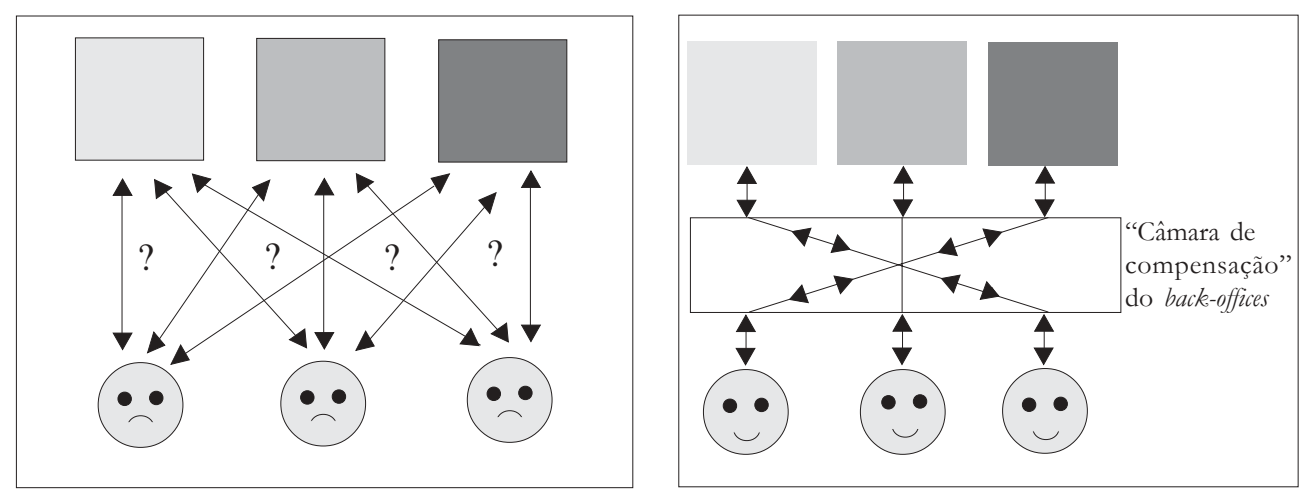
ser acessados). O objetivo da câmara de compensação do CBSS é, portanto, identificar e rastrear informações, independentemente de seu formato, um mecanismo altamente inteligente de troca de dados e não apenas uma grande base centralizada.

Os usuários, nesse caso, são os diferentes empregadores, cada qual com diferentes sistemas de dados e formatos, que, ademais, necessitam comunicar-se com uma variedade de instituições de seguridade social, as quais, por sua vez, utilizam diferentes sistemas de dados relativos à seguridade social, a férias, a doença, a acidentes, a pensões familiares de cada um dos empregados. Possibilitar a interoperabilidade e uma troca de dados bem-sucedida entre todas essas distintas organizações e sistemas é o papel da câmara de compensação do CBSS. Cada empregador necessita processar dados obtidos de diferentes instituições de seguridade social a partir de seu próprio sistema. A câmara de compensação não realiza esse processamento, mas oferece um mecanismo de troca para que o empregador receba a informação requerida, independentemente de sua proveniência, em um formato que ele possa compreender.

\section{Tipos genéricos de interação entre o usuário e o órgão}

Diversas interações entre o usuário (representado pelo front-office) e o órgão (representado pelo back-office) exibem grande número de atributos similares, se não idênticos. São os casos, por exemplo, da interface com o usuário, da funcionalidade da web, do acesso a informações tanto genéricas quanto específicas, da obtenção, preenchimento e devolução de formulários, do envio de dúvidas, da gestão de identidade, dos pagamentos, etc. Da mesma maneira, na interface adminis- trativa, os órgãos precisam prover tudo o que já foi mencionado, além, obviamente, da digitalização e racionalização dos processos de trabalho, da garantia de segurança e proteção de dados, da implementação e utilização efetiva de conceitos de gestão do conhecimento, do uso de padrões em arquiteturas, formatos de dados, linguagens, semântica e sintaxe, da conexão com outros back-offices e órgãos, da avaliação das necessidades da equipe e de suas habilidades e da oferta de treinamento, etc. Há um oceano de potenciais similaridades entre os vários tipos de serviços on-line, pela forma como eles complementam os serviços tradicionais e como a reorganização do back-office ocorre. Mesmo que dado serviço ou conjunto de serviços não apresentem tais similaridades no início, é provável que elas apareçam como resultado da reavaliação, do redesenho e da digitalização que vier a se suceder. De fato, trata-se de uma importante força motriz da reflexão sobre a digitalização.

Economia de escala e de escopo podem, assim, trazer benefícios qualitativos e eficiência, por meio da padronização de algumas características comuns, como forma de poupar recursos, manter a simplicidade, facilidade de manutenção, atualização e uso (seja pelo usuário final, seja pela equipe) e reutilização de atributos desejáveis. Esses benefícios claros dão força ao desenvolvimento e uso de tipos genéricos de interação entre um usuário e um órgão, possibilitando a implementação de serviços consistentes de forma rápida e eficiente em termos financeiros. São sistemas que podem ser disponibilizados por um preço relativamente baixo, ser desenhados para tornarem-se localmente customizáveis e se adaptar a qualquer sistema: o provedor local pode, por exemplo, abrigar um serviço a partir de 

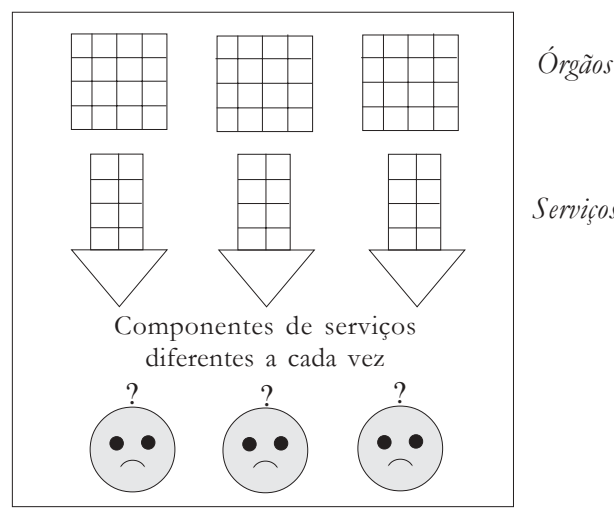

seu próprio website ou administrar o serviço diretamente do sítio de seu desenvolvedor/provedor. Dessa maneira, o desenvolvedor do serviço pode oferecer componentes de serviço digital por um preço acessível até mesmo a órgãos locais e, mais importante, sob medida para as necessidades específicas daquela localidade.

Essa abordagem segue uma tendência geral que aponta para três aspectos: 1) a centralização do back-office e a descentralização do front-office; 2) o desenvolvimento de portais e 3) a crescente facilidade e vantagem, em termos de custo-benefício, da programação de sistemas de interface, tanto ao usuário quanto à administração.

Um exemplo relevante de boa prática no uso de tipos genéricos e modulares de interação entre usuário e órgão é o portal do cidadão dinamarquês "Net.citizen". Esse pacote de serviços utiliza quatro tipos genéricos de interação entre o cidadão e o órgão público, modulados em ambiente Microsoft.net, cada qual utilizado como template. Quando a KMD, o desenvolvedor nacional do serviço, desenvolve, por exemplo, um serviço para o Net.citizen, ela o faz em cooperação com um ou mais municípios (os órgãos locais que irão levar adiante os serviços), tidos como líderes na abordagem de serviços digitais. Essa cooperação permite à KMD conduzir

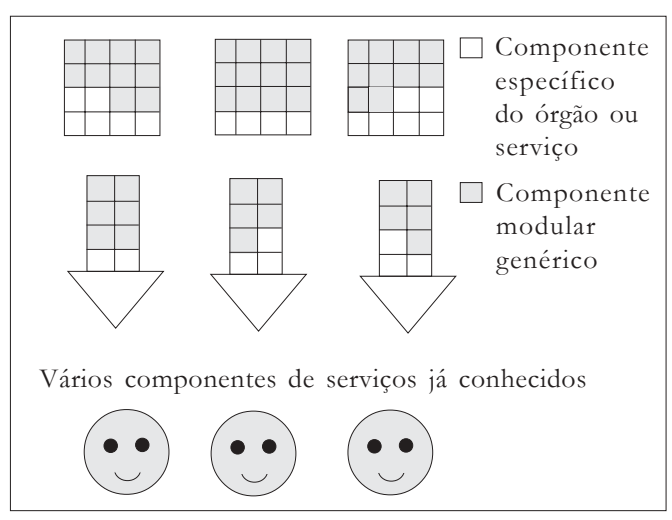

estudos e projetos de reengenharia de processos (Business Process Reengeneering) para desenvolver sistemas e planos de implementação em contexto ótimo. Quando a KMD, na seqüência, passa a comercializar seus componentes de serviços modulares e serviços de suporte, pode, assim, definir, de forma bastante específica, as áreas onde esses produtos podem trazer ganhos em eficiência.

A experiência da KMD mostra que qualquer reorganização e/ou medidas de redução de gastos na área de recursos humanos deve acontecer simultaneamente à implementação do serviço. Se os sistemas são incorporados sem tais mudanças, pode-se tornar muito difícil impulsionar mudanças organizacionais e resultados na produtividade.

O portal dinamarquês também exemplifica como módulos de serviços destinados aos usuários podem ser desenvolvidos por uma parceria público-privada. A KMD não faz parte de uma estratégia geral de governo eletrônico. No entanto, todos os municípios na Dinamarca são parceiros do Net.citizen, sendo a KMD de propriedade de uma organização central que reúne todos os municípios dinamarqueses. Nesse sentido, o Net.citizen pode ser considerado uma parceria público-privada destinada a garantir a efetividade da implementação e 
o desenvolvimento de soluções de serviços digitais em todas as municipalidades dinamarquesas. O papel da KMD, entretanto, é também típico de uma organização (independente de ser pública ou privada) que desenvolve e promove, em nível nacional (ou federal), templates comuns, serviços genéricos horizontais (pagamento e autenticação de usuário, por exemplo). A KMD desenvolve, comercializa e implementa tais componentes de serviços modulares como parte do pacote do portal, mas também outros serviços não necessariamente utilizados para esse fim. Assim, o desenvolvimento e o uso de componentes genéricos ou modulares de serviço não se limitam a portais, mas constituem também uma estratégia importante e mais abrangente.

Outros exemplos são:

- imposto sobre a renda de pessoas físicas e serviços ambientais na Finlândia. A plataforma TYVI constitui a espinha dorsal de um conjunto de serviços, alguns dos quais não estão presentes nesta pesquisa, provendo suporte à transferência padronizada de dados de um aplicativo a outro ou entre usuários de grande porte, hoje baseado no padrão Edifact, embora o uso do XLM esteja em vias de expansão. A TYVI oferece soluções modulares de baixo custo, fáceis de serem implementadas para outros serviços e em outros ambientes;

- portal "HELP", de ajuda ao cidadão, na Austria, que desenvolveu módulos préfabricados como modelos de aprendizado e aperfeiçoamento para disponibilizar mais rapidamente outros serviços on-line. $\mathrm{O}$ HELP trabalha com componentes modulares que podem interoperar com qualquer procedimento de governo eletrônico na Áustria. O portal integra hoje transações entre estados e municípios dentro da estrutura federal e deverá prover também serviço em nível nacional. A meta para 2005 é passar a prestar todos os serviços administrativos de forma on-line na Áustria;

- portais de negócios na Espanha e Suécia. $\mathrm{Na}$ Espanha, os dez serviços destinados a pessoas jurídicas estão situados em um único template, que consiste na submissão de dados, no recebimento de notificação do montante a ser pago, na realização de pagamentos, via portal, com utilização de assinaturas digitais, na validação da assinatura digital, na conexão do usuário ao banco e no pagamento, via portal na Internet, com NRC (número de referência completo). Na Suécia, o Conselho Tributário Sueco é pioneiro no desenvolvimento baseado em componente. Priorizou-se a criação de interfaces e funções modulares, mas em estreita relação com serviços específicos, também destinados a demandas individualizadas. Todos os componentes encontram-se em estrutura de Internet, formada por um componente web-client e um componente de servidor baseado em Java. Serviços voltados para os eleitores incluem declarações e recolhimentos de impostos (pessoas físicas e jurídicas), registros nacionais, e-democracia (candidaturas a eleições gerais), etc. Os dois portais - espanhol e sueco - criaram seus serviços aos eleitores com base em infraestruturas integradas entre diferentes órgãos e back-offices já existentes. O desenho e a implementação tornaram-se muito mais fáceis nesse caso do que se tivessem começado do zero.

Além desses, há exemplos em que componentes padronizados e modulares são utilizados unicamente entre back-offices, isto é, não fazem suporte diretamente a um usuário no front-office. Na Dinamarca, por exemplo, tais componentes habilitadores facilitam a interoperabilidade entre órgãos (normalmente entre estado e município), com efeitos racionalizadores 
e reorganização substancial, muito embora não haja cidadãos ou empresas como usuários finais.

Outro tipo de componente de serviço habilitador é o serviço horizontal (ou auxiliar), como o de pagamento ou segurança (gestão de identidade), que pode ser aproveitado por outros usuários. A Dinamarca está em via de adotar a assinatura digital para dar suporte a transações seguras, como o faz o chamado "e-box", já em uso nos portais dinamarqueses para garantir a segurança das transações monetárias. Esse desenvolvimento modular indica que a maioria dos serviços públicos a serem oferecidos em futuro próximo não criará ou implementará sistemas e padrões próprios de segurança e pagamento, mas, ao contrário, usará aqueles já dotados de massa crítica, resultante de seu uso público e privado amplamente difundido e, assim, vão-se tornar, na prática, padrões no mercado. Tanto o "e-box" dinamarquês como a assinatura digital são desenvolvidos e geridos por parcerias público-privadas. Esse tipo de serviço habilitador poderia facilitar a integração do back-office, criando padrões para a troca de dados.

\section{Portais}

Uma das principais tendências em governo eletrônico nos últimos anos vem sendo o desenvolvimento de portais. Um portal, geralmente um website, oferece aos usuários uma visão geral dos serviços e do acesso a eles, na maioria das vezes concentrado em um único lugar, dispensando o usuário de visitar websites distintos para cada serviço. Os serviços em um portal mantêm alguma relação entre eles, de forma que o usuário típico precisará ou desejará recorrer a dois ou mais deles para completar determinada tarefa. Uma vantagem dos portais é que serviços antes separados aparecem agora com o conceito de serviço único, oferecido em uma série de etapas ou opções. É mais visível ao usuário também quando os dados já inseridos reaparecem em cada etapa, poupando-lhe de digitá-los novamente. Um portal também abre caminho para que serviços horizontais, como pagamentos e segurança (gestão de autenticação), possam ser facilmente acessados a partir de qualquer serviço ou combinação deles.

Um atributo distintivo de um portal emerge do fato de que seu princípio organizacional não se relaciona aos backoffices ou às estruturas e aos interesses dos órgãos a ele vinculados, mas à perspectiva do usuário. Por exemplo, um portal pode ser organizado:

- para cidadãos, sobre acontecimentos, episódios ou ciclos de suas vidas, como nascimento, casamento, morte, emprego/ desemprego, educação, condições de vida, moradia, trabalho, esporte e lazer, etc.;

- para empresas, sobre acontecimentos como abertura de empresa, financiamento, aspectos legais e regulatórios, transações e operações comerciais, instalações e ambiente, impostos e finanças, declarações de impostos e outras obrigações, inovação, expansão da empresa, venda ao governo, fechamento e venda de empresa, etc.

Outra abordagem que se sobrepõe, porém, a essa e parece ser mais comum entre os casos de boa prática examinados neste estudo é a organização do portal em torno de conceito mais amplo de grupos-alvo de usuários e não em torno de eventos vinculados a todos os cidadãos ou a todas as empresas, embora, nesse caso, também seja possível haver recortes como, por exemplo, idade (portais destinados à terceira idade ou a jovens) e porte do empreendimento (grande empresa, 
empresa de pequeno porte). A idéia, aqui, é reunir um conjunto de serviços ou componentes funcionais apropriados para cada um dos grupos-alvo.

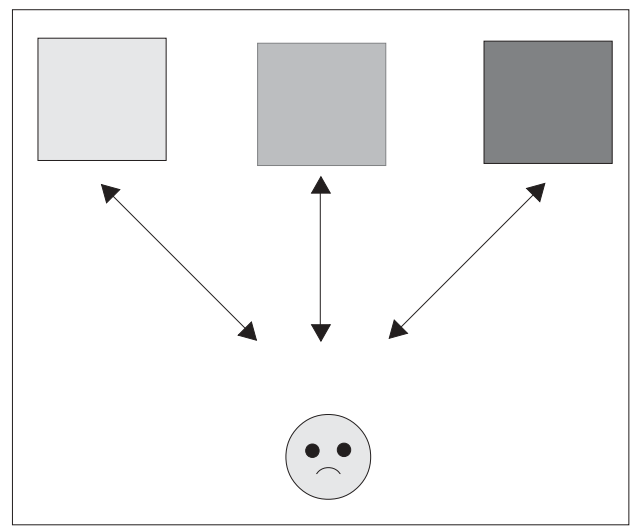

Um exemplo relevante ${ }^{14}$ de boa prática no desenho, na implementação e na disponibilização de portais é o portal de impostos sobre empresas da Espanba. A Agencia Tributaria (AEAT) é encarregada da gestão tributária e aduaneira em nível nacional, vinculada a qualquer pessoa (física ou jurídica). Um conjunto de dez serviços empresariais foi disponibilizado sob forma de um portal específico para tributos vinculados ao comércio, que incluía o imposto sobre a renda das empresas, o imposto sobre o valor agregado, as contribuições para empregados, entre outros. As informações submetidas pelos usuários empresariais são armazenadas de forma centralizada, permitindo sua reutilização em todos os serviços cobertos pelo portal. A maioria deles foi desenvolvida e implementada com base em um template genérico, tornando mais fácil o seu uso, a sua interoperabilidade e seu retorno em termos de custo-benefício.

O portal conduz o usuário a uma série de etapas e opções. Em primeiro lugar, exige-se da empresa o envio de seus dados e, com base nisso, é-lhe informado o montante do tributo a ser recolhido. Isso pode ser feito por meio do portal da AEAT ou pelos meios tradicionais. Se feito com a utilização do portal, é preciso

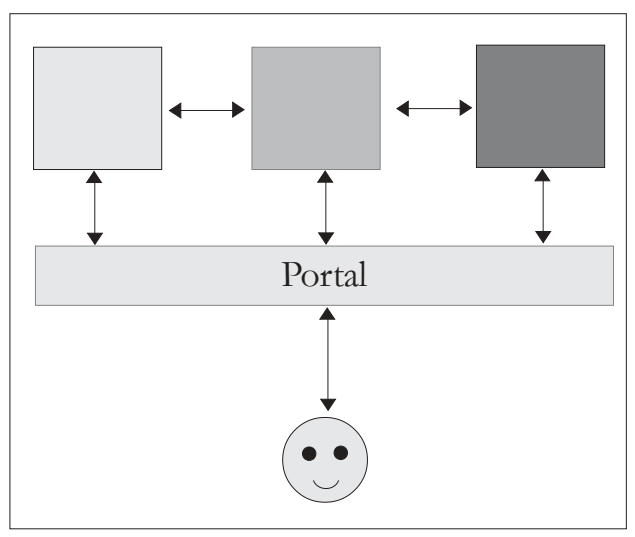

assinatura digital, fornecida pela AEAT, para autenticação. Uma vez validada, o serviço conecta o usuário diretamente ao banco associado, e o pagamento pode ser realizado com um número de referência completo (NRC) gerado unicamente para esse fim. A empresa, então, deve submeter uma declaração, com a aposição de assinatura digital - que também é concedida pela Autoridad Pública de Certificación Española (Ceres) e por outros centros autorizados -, fazendo referência ao NRC. A assinatura digital é verificada pela Ceres e o NRC, cotejado com o do banco. Se a declaração de imposto resulta em restituição, a informação é enviada ao sistema de restituição padrão, no qual uma ordem de restituição é gerada. Antes que o pagamento seja efetivado, o sistema checa se não constam registros de débitos. Em caso positivo, a restituição destina-se primeiramente ao acerto desse débito. Depois disso, é feito o recálculo da restituição, que pode gerar uma exigência de pagamento.

O portal espanhol foi inicialmente disponibilizado somente para grandes empresas em julho de 1998. A partir de 
janeiro de 1999, passou a ser obrigatória para essas grandes empresas a declaração do imposto por meio do portal. Em vista das vantagens apresentadas pelo portal, muitas pequenas e médias empresas passaram a demandar um serviço similar, que passou a ser oferecido a partir do terceiro trimestre de 1999. Foram realizadas intensas campanhas informativas e publicitárias.

\section{Serviços proativos}

À medida que os back-offices se integram e se tornam capazes de compartilhar dados e fontes, uma estratégia interessante e cada vez mais recorrente no front-office é oferecer serviços proativos aos usuários, nos quais o órgão público competente assume a responsabilidade de iniciar, prestar e cumprir determinado serviço. A necessidade de intervenção do usuário é, assim, minimizada e pode mesmo desaparecer. São os chamados "serviços em via de extinção", que podem ser uma grande vantagem ao usuário, tanto por dispensá-lo da necessidade de lembrar quando, onde e como aquele serviço deve ser usado, como por poupar-lhe tempo e esforço. Aos serviços de legislação complexa, regras múltiplas e procedimentos de difícil compreensão ao usuário médio, a proatividade também constitui uma vantagem.

A capacidade de oferecer serviços proativamente resulta em importantes benefícios para o órgão: há garantia de que o serviço foi ativado no momento e no lugar certo, foi correta e eficientemente realizado e não foi atrasado pela demora do usuário no cumprimento de determinadas responsabilidades e na prestação de dados. Normalmente, esse tipo de serviço demanda dados que já se encontram registrados no setor público ou que podem ser facilmente obtidos de terceiros (por exemplo, empregadores) por via legal. O uso desses dados segue as normas que regem a prestação de serviços dessa natureza, que podem ser: um pagamento ao usuário ou, ao contrário, uma exigência de pagamento por parte dele, uma concessão de direitos ou uma imposição de obrigações, etc. $\mathrm{Na}$ maioria dos casos, o usuário é obrigado a confirmar a aceitação do serviço antes de sua implementação, embora, em alguns deles, a não-resposta seja entendida como aceitação. Neste último caso, o serviço, de fato, "desaparece" em face do usuário, ainda que lhe seja prestado e lhe implique benefícios ou obrigações.

A proatividade não é relevante a todos os tipos de serviços e tende a ser restrita àqueles nos quais toda - ou quase toda - a
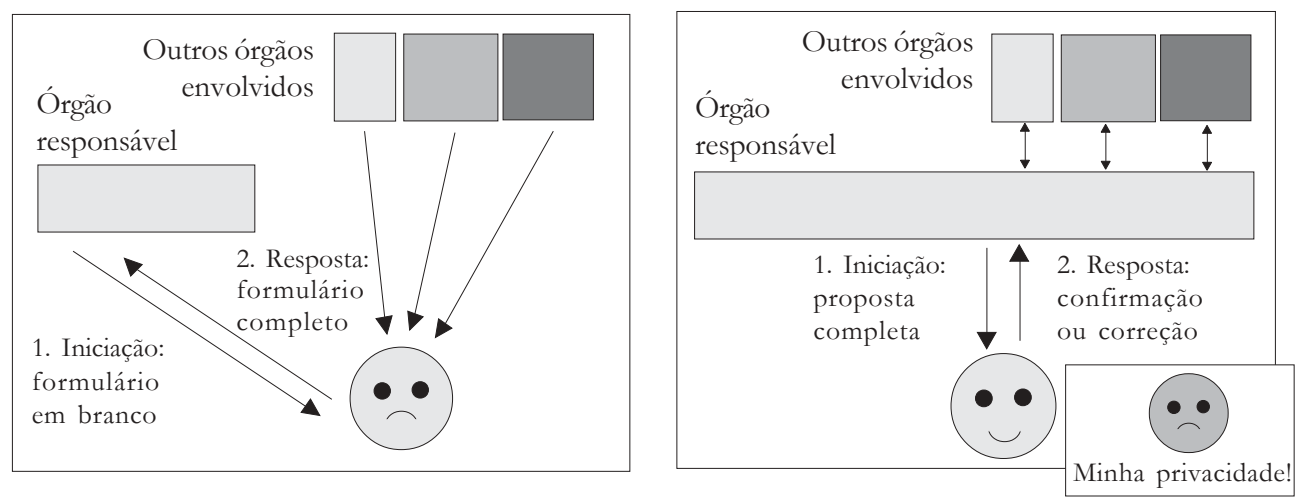
informação necessária já exista no setor público. O órgão responsável chama para si, então, toda a responsabilidade e o controle imediato referentes àquele serviço, que antes cabiam ao usuário, oferecendolhe atendimento razoavelmente individualizado sem a necessidade de ação ou iniciativa por parte deste. Grande parte desses serviços caracteriza-se pelo fato de:

- o órgão ser legalmente obrigado a implementá-lo;

- o próprio órgão possuir todos, ou quase todos, os dados relativos ao usuário (inclusive pessoais) necessários para a prestação do serviço, ou conseguir obtê-los, por vias legais, de outros órgãos ou organizações, o que também reduz ou dispensa a obrigatoriedade de o usuário receber e guardar os recibos das transações;

- haver grande integração e interoperabilidade entre back-offices;

- não existirem impedimentos legais para que os órgãos possam utilizar os dados que eles possuem e o usuário, de sua parte, não se opor ao seu uso.

Um exemplo relevante ${ }^{15}$ de boa prática em serviços proativos vem das pensões familiares na Irlanda. Aqui, três avanços interligados foram centrais para possibilitar a provisão do novo serviço proativo de assistência à criança. Em primeiro lugar, a DSFA (órgão de assistência à criança) implementou, em 2001 e 2002, um significativo programa de mudança organizacional, com a incorporação de novas tecnologias, o que possibilitou o recebimento de notificações de nascimentos eletronicamente com base no serviço de registro civil, além de promover inúmeras melhorias ao serviço existente tanto para usuários como para os servidores. Paralelamente, foi dado início à modernização nos serviços e processos irlandeses de registro civil de nascimentos, mortes, casamentos, entre outros, que incluiu a digitalização de arquivos e a informatização do processo de registro e emissão de certidão do Escritório de Registro Geral Irlandês (Irish General Register Office). Finalmente, o projeto "Reach" (iniciativa nacional chave no desenvolvimento e coordenação do governo eletrônico na Irlanda) implementaria um serviço de mensagens eletrônicas entre órgãos, que iria garantir a interoperabilidade de dados, como a notificação eletrônica de registros de nascimentos.

Graças a esses avanços, os pais não são mais obrigados a obter cópias físicas de certidões de nascimentos e a submetê-las à DSFA para requerer o benefício à criança. O trabalho dos servidores que realizam a análise dos pedidos também foi bastante reduzido, à medida que o novo sistema realiza a autenticação dos pedidos automaticamente por meio da interligação com o Escritório de Registro. No caso de solicitação do benefício ao primeiro filho, um formulário parcialmente preenchido é emitido automaticamente aos pais, o que diminui a quantidade de informações a serem colocadas no formulário e encoraja os pais a aderirem a esse serviço. Para o segundo filho, não há sequer o envio de formulários: o pagamento é iniciado de forma proativa e automática, sem iniciativa alguma dos pais (salvo em caso de adoção). Em alguns poucos casos - de famílias recentemente instaladas na Irlanda -, esse serviço não é possível, mas é disponível o seu acesso on-line.

\section{Maior responsabilidade e con- trole aos usuários - um self-service para quem usa}

Como se procurou mostrar na seção anterior, à medida que back-offices se tornam mais integrados e habilitados para 
compartilhar dados e fontes, é possível oferecer serviços proativos que requerem pouca ou nenhuma responsabilidade ou ação do usuário. Outra importante estratégia que decorre dessa mesma evolução aponta que também é viável oferecer ao usuário não menor, mas maior responsabilidade e controle sobre um dado serviço. No caso de serviços proativos, a digitalização e a interoperabilidade de dados possibilitam ao órgão - e não ao usuário - assumir a maior parte, se não toda, da responsabilidade e do controle pelo serviço. No entanto, o contrário também é plausível: garantindo-se transparência aos usuários, eles podem ter acesso e controle diretos sobre determinados dados e componentes de serviços. Esses dados, por sua vez, estariam disponíveis eletronicamente onde quer que se encontrem no setor público, permitindo seu acesso e uso por iniciativa do usuário.

Nesse sentido, transferir a responsabilidade sobre o serviço e seu controle ao órgão ou ao usuário é uma possibilidade que se abre com a digitalização e a interoperabilidade de dados. Optar por um ou outro é, mais do que uma questão técnica, uma decisão política, calcada no marco legal, ético e cultural prevalecente.

Conferir ao usuário o controle e a responsabilidade pelo serviço pode trazer vantagens significativas, porque permite ao usuário determinar quando, onde e como o serviço será utilizado, explorar atributos específicos dele, bem como fazer o acompanhamento de seu progresso, utilizandose, por exemplo, as opções de busca e rastreamento. Outras vantagens dizem respeito à capacidade de verificar e corrigir informações incorretas ou desnecessárias, de atualizar mais rapidamente os dados e de assegurar ao setor público a posse apenas daqueles dados a que faz jus e/ou que o usuário deseje que a administração pública tenha. Por fim, e talvez mais importante para a moderna democracia, a transferência de algum grau de responsabilidade e controle sobre determinados serviços ao usuário pode ser vista como parte do ethos de um governo mais aberto, transparente e acessível, particularmente se as regras, leis e normas que a regem forem suficientemente simples e compreensíveis para que o usuário comum possa usufruir o serviço. Uma sociedade regida por estruturas legais e regulatórias obtusas, confusas ou compreendidas apenas por especialistas pode ser apontada como muito pouco democrática.

Para o órgão público, essa transferência também traz importantes benefícios, que incluem uma provável redução significativa de tarefas como inserção de dados e
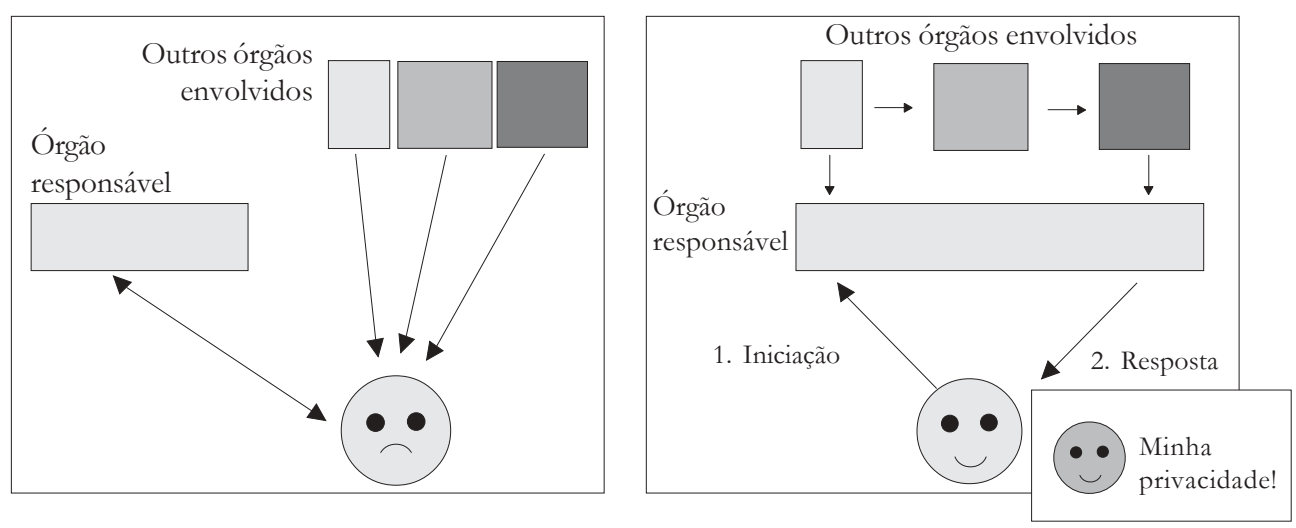
validação, liberando, assim, a equipe e outros recursos para outras funções. Em algumas circunstâncias pré-definidas, o órgão pode mesmo tornar-se completamente desobrigado a disponibilizar aquele serviço, tendo em vista que o ônus de iniciá-lo cabe ao usuário. Se este for apropriadamente informado, equipado e treinado para tanto, isso significa que o serviço terá um público-alvo muito mais específico do que seria, se fosse ofertado a todos indistintamente ou se coubesse unicamente ao órgão competente toda a decisão sobre a definição do público-alvo daquele serviço.

Não se trata de estratégia relevante para todos os tipos de serviço e parece mais adequada àqueles casos em que tipicamente:

- o órgão competente não é legalmente obrigado a iniciá-lo;

- ele não possui grande parte dos dados necessários (particularmente os que se referem a dados pessoais) em seus registros ou nos de outros órgãos para prestar o serviço;

- pode haver restrições legais para o compartilhamento de dados pessoais do usuário entre os diferentes órgãos, ainda que a ênfase recaia sobre a necessidade de aumentar a integração e a interoperabilidade entre back-offices, de forma que informações sejam facilmente acessíveis pelos usuários, independentemente de onde elas se encontrem na administração pública;

- não há barreiras legais, éticas ou técnicas para que o usuário assuma o controle e a responsabilidade.

Um exemplo relevante ${ }^{16}$ dessa boa prática é a matrícula no ensino superior na Finlândia. O principal sistema de informação administrativa da Universidade de Helsinki é dividido em três partes. A primeira delas diz respeito a informações sobre o estudante e é, em grande parte, de controle do próprio aluno. As outras duas referemse a informações sobre cursos e a normas e regulamentos a eles atinentes. Para usar o sistema, o aluno identifica-se e coloca sua senha, que dá acesso a sua página pessoal e a opções específicas do usuário, sob a forma de um menu. O sistema inclui interfaces on-line inteligentes como, por exemplo, menus drop-down explicativos e formulários com funções de autovalidação, que ajudam a diminuir a incidência de erros, justamente por conferirem aos usuários maior controle e responsabilidade, quando se comparam com os formulários em papel. Essa descentralização de tarefas diretamente ao usuário final também poupa significativos recursos e tempo da equipe.

Parte desses serviços é disponível também por telefone celular (WAP, SMS). O estudante tem uma série de opções no menu principal, como a verificação ou, se necessário, a atualização de dados pessoais, registros, créditos de disciplinas e planos de estudos, e pode também inscrever-se em eventos acadêmicos, solicitar históricos escolares, matricular-se na universidade e fazer comentários sobre os cursos. Todos esses atributos são iniciados e controlados pelo aluno. De forma geral, a natureza descentralizada desse sistema permite aos alunos melhor administrar seus estudos. No futuro, haverá também serviços mais orientados aos estudos, tais como a integração dos sistemas de monitoria ao plano pessoal de estudos. A transferência do aluno para outra universidade é hoje também muito mais fácil. Prevê-se também a possibilidade de realizar as provas de uma universidade em local próximo ao estudante, ao invés de fazê-lo deslocar para a unidade responsável.

Um dos principais determinantes para a implementação de serviço descentralizado 
e on-line de matrículas na Finlândia foi a reivindicação dos alunos por maior interatividade e controle do processo. Eles enfrentavam, no sistema tradicional, atrasos, longas filas e precisavam ir a diferentes departamentos. A segurança dos dados é de extrema relevância em sistemas abertos como esse e está sujeita à Lei de Proteção de Dados Pessoais da Finlândia, que exige de órgãos públicos que des- crevam ao público suas políticas de privacidade. O uso externo da informação fornecida pelo aluno na matrícula deve seguir essa lei. Para todos os outros fins (como, por exemplo, sistemas públicos de informações de contato ${ }^{17}$, demandas de informações de outras universidades ou de empregadores, para fins de recrutamento), a cessão de dados pessoais de alunos deve contar com sua aprovação prévia.

\section{Notas}

* Este texto constitui parte do primeiro volume do relatório Reorganisation of government backoffices for better electronic public services - European good practices (back-office reorganisation), apresentado à Comissão Européia em janeiro de 2004. O estudo foi patrocinado pelo Directorate General for Information Society and Media (Diretório Geral para a Sociedade da Informação e Mídia) da Comissão Européia. Tradução de Claudia Asazu e revisão técnica de Leonardo Moreira Figueira.

${ }^{1}$ Comissão Européia. The role of egovernment for Europe's future". Comunicação da Comissão para o Conselho, o Parlamento Europeu, o Comitê Econômico e Social Europeu e o Comitê das Regiões. Bruxelas, 26.9.2003, COM (2003) 567. Final.

${ }^{2}$ Op. cit.

${ }^{3} \mathrm{O}$ código de conduta de benchmarking europeu traz a seguinte definição: "Benchmarking consiste simplesmente em fazer comparações com outras organizações e, com isso, aprender as lições que essas comparações trazem". The European Benchmarking Code of Conduct. Disponível em: $<$ www.benchmarking.gov.uk> (Nota da Tradutora).

${ }^{4}$ Comissão EuropéiA. eEurope - an information societ for all. Lisboa, 23-24 de março, 2000. Disponível em : <http://europa.eu.int/comm/information_society/eeuropa/pdf/com081299_en.pdf>.

${ }^{5}$ Estudo disponível em: <http://europa.eu.int/information_society/eeurope/benchmarking/ list/2002/index_en.htm>.

${ }^{6}$ Conselho das Municipalidades e Regiões Européias sobre o Governo Eletrônico (28/11/01).

${ }^{7}$ O que confirma as conclusões da comunicação da Comissão sobre o impacto da e-economy nas empresas européias (COM (2001) 711, novembro de 2001).

${ }^{8} \mathrm{O}$ back-office corresponde à "retaguarda administrativa", isto é, a parte da prestação governamental atinente aos procedimentos internos, não visíveis ao cidadão, em oposição ao front-office, o "balcão de atendimento", locus da interface entre administração pública e sociedade (Nota do Revisor).

${ }^{9}$ No ordenamento jurídico brasileiro, o órgão público possui competência, estrutura, quadro de servidores e poderes funcionais próprios. Ainda que não dotados de personalidade jurídica própria, consideramos que se trata da definição que mais se aproxima daquela de government agency dada no relatório. 
${ }^{10}$ Sistema eletrônico de aquisição de livros escolares desenvolvido na Áustria, envolvendo a administração pública, as escolas, as livrarias e as editoras.

${ }^{11}$ Outros exemplos citados pelo relatório são: licença para construção em Esslingen, Alemanha, e em Bolonha, Itália, matrícula em instituição de ensino superior, na Finlândia e no Reino Unido, e desenvolvimento de portal, na Áustria e Dinamarca

${ }^{12} \mathrm{O}$ relatório cita também os exemplos de licitação pública na Áustria, para a compra de livros escolares, do serviço de concessão de licenças ambientais na Finlândia e do portal destinado a empresas na Espanha.

${ }^{13}$ Outros exemplos são o imposto de renda de pessoa física, o imposto sobre o valor agregado (IVA) pago pelas empresas, imposto sobre a renda das pessoas jurídicas e licenças ambientais na Finlândia.

${ }^{14}$ Outros exemplos são: portais destinados aos cidadãos na Áustria (HELP) e na Dinamarca (Net.Citizen), portal de impostos sobre pessoas jurídicas na Suécia, impostos sobre a pessoa jurídica e sobre o valor agregado na Grécia, na Irlanda e em Portugal e o sistema finlandês TYVI.

${ }^{15}$ Há também os exemplos da declaração de imposto de renda na Finlândia, da declaração de impostos incidentes sobre empresas na Espanha, das pensões familiares na Espanha e das contribuições sociais pagos pelas empresas na Bélgica.

${ }^{16}$ Os outros exemplos citados são os das bolsas de estudos na Dinamarca e nos Países Baixos, da matrícula em ensino superior no Reino Unido, das bibliotecas públicas na Dinamarca e do boletim de ocorrência policial na Finlândia e o do portal do cidadão na Dinamarca.

${ }^{17}$ Tais como catálogos telefônicos (Nota da Tradutora).

Jeremy Millard e Jonas Iversen, do Danish Technological Institute (Dinamarca, <www.danishtechnology.dk>) e Herbert Kubicek, Hilmar Westholm e Ralf Cimander, do Institut für Informationsmanagement Bremen, da Universidade de Bremen (Alemanha, <www.ifib.de>), compõem a equipe responsável pela elaboração deste relatório. 